\section{Syntheses and Structure of Molybdenum(0) Dimers Based on Tetracyanobiimidazole}

\section{PAUL G. RASMUSSEN}

Department of Chemistry, University of Michigan, Ann Arbor, Mich. 48109, U.S.A.

\section{and JOAN CARLES BAYÓN}

Department de Quimica Inorgànica, Facultat de Ciencies, Universitat Autònoma de Barcelona, Bellaterra, Barcelona, Spain

Received July 23, 1983

In a recent preliminary communication [1] we reported the synthesis and properties of a novel new compound $4,4^{\prime}, 5,5^{\prime}$-tetracyano-2, $2^{\prime}$-biimidazole $\left(\mathrm{H}_{2} \mathrm{Tcbiim}\right)$.<smiles>N#Cc1nc(-c2nc(C#N)c(C#N)[nH]2)[nH]c1C#N</smiles>

As we anticipated, the strongly electron withdrawing cyano substituents profoundly alter the electronic structure compared to the parent biimidazole system we investigated earlier $[2,3,4]$. The $\mathrm{H}_{2}$ Tcbiim system is far more acidic and always forms complexes as the dianion. It retains the potential for forming aromatic bridges between pairs of metal ions however, and interactions between such linked metal centers has been of increased interest lately, especially in the context of intermolecular redox reactions. $\mathrm{H}_{2}$ Tcbiim reacts readily with metals in low oxidation states to yield binuclear complexes and we have described the syntheses and reactions of $\mathrm{Rh}(\mathrm{I})$ and $\operatorname{Ir}(\mathrm{I})$ species elsewhere [5]. We have also demonstrated the bridging of $\mathrm{Cu}(\mathrm{I})$ ions by $\mathrm{Tcbiim}^{2-}$ and we are investigating this system further [6]. Beck and coworkers were able to form dimers of zero-valent molybdenum using biimidazole [7] and we report here some analogous compounds based on $\mathrm{H}_{2}$ Tcbiim. The unique properties of the percyano substituted imidazole make these compounds easier to prepare and somewhat more tractable.

Reaction of the sodium salt of Tcbiim ${ }^{2-}(1 \mathrm{mmol})$ with $\mathrm{Mo}(\mathrm{CO})_{6}(2 \mathrm{mmols})$ in $25 \mathrm{ml}$ of diglyme for four hours at $60 \mathrm{C}$ under $\mathrm{N}_{2}$ produced an orange solution. Addition of the stoichiometric amount of $\mathrm{Ph}_{4} \mathrm{AsCl}$ in $20 \mathrm{ml}$ ethanol, stripping the solvents and extraction with $\mathrm{CH}_{2} \mathrm{Cl}_{2}$ yields a yellow solution from which the yellow microcrystalline compound
$\left[\mathrm{Ph}_{4} \mathrm{As}_{2}\left[(\mathrm{CO})_{4} \mathrm{Mo}(\mathrm{Tcbiim}) \mathrm{Mo}(\mathrm{CO})_{4}\right]\right.$ can be isolated by evaporation under vacuum. The IR spectrum of the complex shows the nitrile band of the ligand at $2243 \mathrm{~cm}^{-1}$ and four carbonyl peaks at $2017,1899,1864$, and $1828 \mathrm{~cm}^{-1}$ corresponding to the $\mathrm{C}_{2 \mathrm{v}}$ local symmetry. The complex $\left[\mathrm{Et}_{4} \mathrm{~N}\right]_{2}$. $\left[(\mathrm{CO})_{3}\left(\mathrm{PPh}_{3}\right) \mathrm{Mo}(\mathrm{Tcbiim}) \mathrm{Mo}\left(\mathrm{PPh}_{3}\right)(\mathrm{CO})_{3}\right] \cdot \mathrm{CH}_{3} \mathrm{CN}$ is prepared by stirring at room temperature $1 \mathrm{mmol}$ of $\left(\mathrm{Et}_{4} \mathrm{~N}\right)_{2} \mathrm{Tcbiim}$ and $2 \mathrm{mmol}$ of $\mathrm{fac}-\mathrm{Mo}\left(\mathrm{CH}_{3} \mathrm{CN}\right)_{3}-$ $(\mathrm{CO})_{3}$ in $20 \mathrm{ml}$ of dry acetonitrile for two hours. Addition of $2 \mathrm{mmol}$ of triphenylphosphine; further stirring at $60 \mathrm{C}$ and reduction of the volume, leads to precipitation of the yellow microcrystalline product. The IR spectrum shows a nitrile band at $2230 \mathrm{~cm}^{-1}$ and three carbonyl stretches at 1900, 1786, and $1761 \mathrm{~cm}^{-1}$. Crystals of this compound suitable for x-ray diffraction were grown by diffusion of ether into an acetonitrile solution. Crystal data: $\mathrm{Mo}_{2} \mathrm{P}_{2} \mathrm{O}_{6} \mathrm{~N}_{11} \mathrm{C}_{70} \mathrm{H}_{73}$; space group $\mathrm{P} 21 / \mathrm{n} ; a=11.241$ (3) $\AA, b=27.350(13) \AA, c=12.350(6) \AA ; \beta=$ 103.01(3); $V=3699(2) \AA^{3} ; Z=2$. Refinement of 3770 observed reflections led to a final $R=4.9 \%$. Details of data collection and procedures and programs used have been described previously [8].

TABLE I. Selected Bond Distances ( $(\AA)$. E.s.d. in Parenthesis.

\begin{tabular}{lll}
\hline Mo & C41 & $1.929(7)$ \\
Mo & C51 & $1.932(7)$ \\
Mo & C61 & $1.961(7)$ \\
Mo & Ni & $2.316(5)$ \\
Mo & N3 & $2.316(5)$ \\
Mo & P & $2.563(2)$ \\
P & C31 & $1.818(7)$ \\
P & C21 & $1.848(7)$ \\
P & C11 & $1.854(6)$ \\
C41 & O41 & $1.171(8)$ \\
C51 & 051 & $1.168(7)$ \\
C61 & 061 & $1.158(8)$ \\
N1 & C2 & $1.330(7)$ \\
N1 & C5 & $1.380(7)$ \\
C2 & N3 & $1.343(7)$ \\
C2 & C2 & $1.427(11)$ \\
N3 & C4 & $1.359(7)$ \\
C4 & C5 & $1.403(9)$ \\
C4 & C6 & $1.425(9)$ \\
C5 & C7 & $1.407(9)$ \\
C6 & N4 & $1.124(8)$ \\
C7 & N5 & $1.150(8)$ \\
\hline
\end{tabular}

The structure with atom labels is shown in Fig. 1. Selected bond distances and angles are given in Tables I and II. The complex anion is centrosymmetric with an inversion center located between the two equiva- 


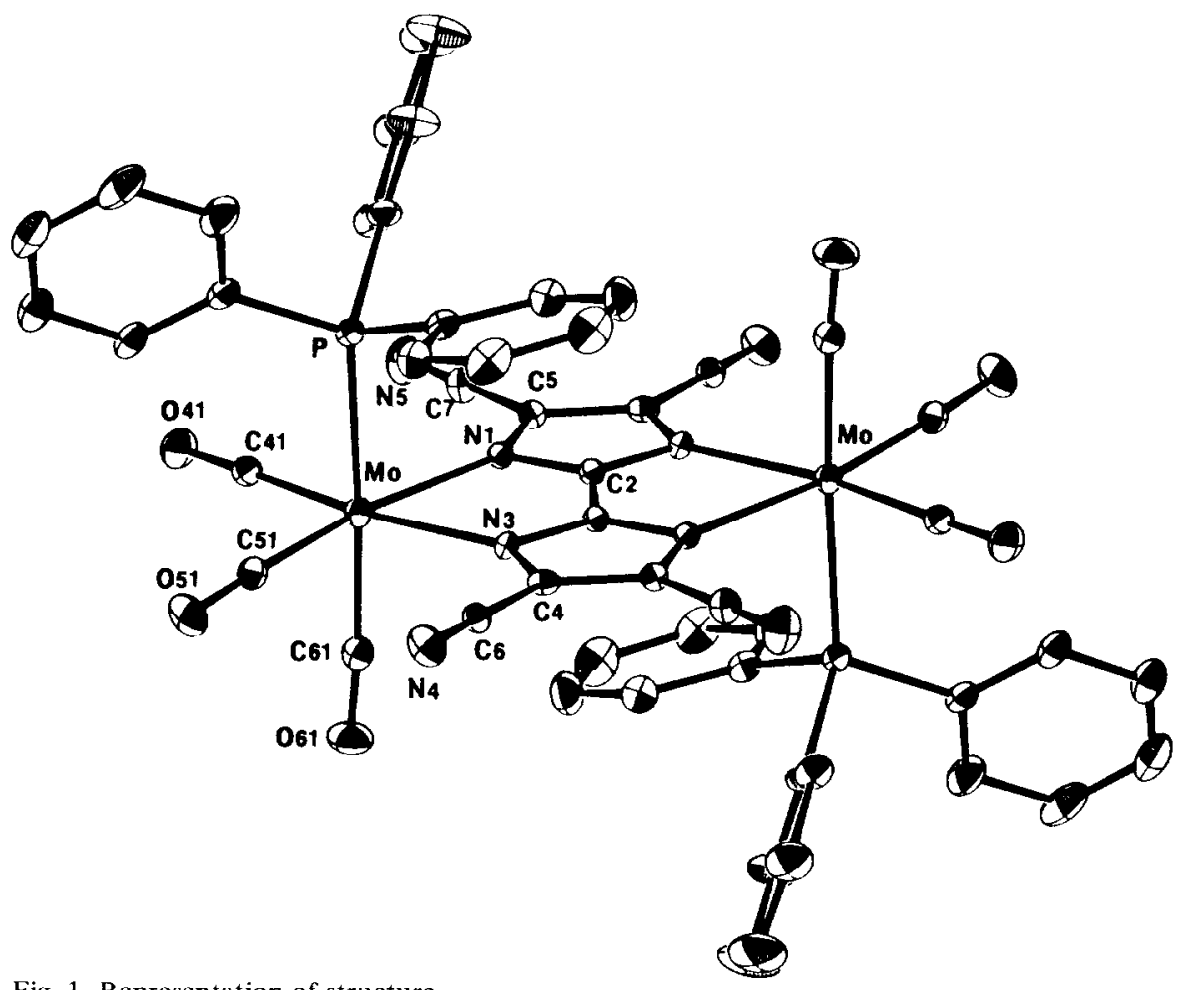

Fig. 1. Representation of structure.

TABLE II. Selected Angles $\left({ }^{\circ}\right)$. E.s.d. in Parenthesis.

\begin{tabular}{|c|c|c|c|}
\hline$C 41$ & Mo & C.51 & $89.01(28)$ \\
\hline $\mathrm{C} 41$ & Mo & C61 & $88.64(28)$ \\
\hline $\mathrm{C} 41$ & Mo & N1 & $97.78(22)$ \\
\hline $\mathrm{C} 41$ & Mo & $\mathrm{P}$ & $91.56(20)$ \\
\hline C51 & Mo & C61 & $83.65(27)$ \\
\hline C51 & Mo & $\mathrm{N} 3$ & $98.51(23)$ \\
\hline $\mathrm{C} 51$ & Mo & $\mathrm{P}$ & $92.25(20)$ \\
\hline C61 & Mo & $\mathrm{N} 1$ & $93.05(22)$ \\
\hline C61 & Mo & N3 & $94.28(23)$ \\
\hline N1 & Mo & $\mathrm{P}$ & $90.98(13)$ \\
\hline N3 & Mo & $\mathrm{P}$ & $86.04(13)$ \\
\hline $\mathrm{N} 1$ & Mo & N3 & $79.84(17)$ \\
\hline 041 & C41 & Mo & $178.48(95)$ \\
\hline O51 & C51 & Mo & $176.11(68)$ \\
\hline 061 & C61 & Mo & $175.44(63)$ \\
\hline $\mathrm{C} 2$ & N1 & $\mathrm{C} 5$ & $102.38(47)$ \\
\hline $\mathrm{C} 2$ & N1 & Mo & $111.34(36)$ \\
\hline $\mathrm{C} 5$ & N1 & Mo & $146.16(41)$ \\
\hline N1 & $\mathrm{C} 2$ & N3 & $117.45(49)$ \\
\hline N1 & $\mathrm{C} 2$ & $\mathrm{C} 2^{\prime}$ & $121.65(67)$ \\
\hline N3 & $\mathrm{C} 2$ & $\mathrm{C} 2^{\prime}$ & $120.87(69)$ \\
\hline $\mathrm{C} 2$ & N3 & $\mathrm{C} 4$ & $102.60(49)$ \\
\hline $\mathrm{C} 2$ & N3 & Mo & $111.24(36)$ \\
\hline $\mathrm{C} 4$ & N3 & Mo & $146.16(42)$ \\
\hline N3 & $\mathrm{C} 4$ & $\mathrm{C} 5$ & $109.12(51)$ \\
\hline N3 & $\mathrm{C} 4$ & $\mathrm{C} 6$ & $123.28(59)$ \\
\hline $\mathrm{C} 5$ & $\mathrm{C} 4$ & $\mathrm{C} 6$ & $127.60(56)$ \\
\hline N1 & $\mathrm{C} 5$ & $\mathrm{C} 7$ & $123.10(56)$ \\
\hline $\mathrm{C} 4$ & $\mathrm{C} 5$ & $\mathrm{C} 7$ & $128.46(56)$ \\
\hline N4 & C6 & $\mathrm{C} 4$ & $177.41(74)$ \\
\hline N5 & C7 & $\mathrm{C} 5$ & $178.9(13)$ \\
\hline
\end{tabular}

lent $\mathrm{C} 2$ atoms. The biggest distortion from regular octahedral geometry at the metal is the N1-Mo-N3 angle of 79.8. Similar values for this angle have been found in other structures containing Tcbiim ${ }^{2-}$ [9]. Although not required by the space group, the two $\mathrm{Mo}-\mathrm{N}$ bond lengths are identical and except for the phenyl rings the ion has near $\mathrm{C}_{2 \mathrm{~h}}$ symmetry. The Mo-Mo distance across the bridge is $5.96 \AA$. The tetracyanobiimidazole bridge is planar with negligible deviation, and the molybdenum and equatorial carbonyls lie within $\pm 0.5 \AA$ of this plane. The Mo-C41 and Mo-C42 are only $0.03 \AA$ shorter than Mo-C61 which is trans to the phosphine. This indicates that the tetracyanobiimidazole dianion is nearly as effective a pi acceptor as the phosphine. This is further corroborated by the $\mathrm{CO}$ stretching frequencies in the carbonyl anion which average $20 \mathrm{~cm}^{-1}$ higher than those of corresponding unsubstituted biimidazole complex [7]. Thus tetracyanobiimidazole can be expected to readily bridge low valent metals and to form the basis for a wide variety of organometallic dimers. Furthermore, its greater acidity and solubility make synthetic procedures somewhat simpler compared to the parent biimidazole compound. The synthesis of the phosphine derivative described above takes place by the stepwise substitution of the easily displaced acetonitriles. This procedure can be used to prepare a variety of substituted dimers bridged by tetracyanobiimidazole. We are currently investigating the preparation and reactivity of this class of compounds. 


\section{Acknowledgements}

J. C. B. wishes to thank the Fulbright Commission and the U.S.A.Spain Joint Committee for postdoctoral support.

\section{References}

1 P. G. Rasmussen, R. L. Hough, J. E. Anderson, O. H. Bailey and J. C. Bayón, J. Am. Chem. Soc., 104, 6155 (1982).

2 S. W. Kaiser, R. B. Saillant and P. G. Rasmussen, J. Am. Chem. Soc., 97, 425 (1975).
3 S. W. Kaiser, R. B. Saillant, W. M. Butler and P. G. Rasmussen, Inorg. Chem., 15, 2681 (1976).

4 S. W. Kaiser, R. B. Saillant, W. M. Butler and P. G. Rasmussen, Inorg. Chem., 15, 2688 (1976).

5 P. G. Rasmussen, O. H. Bailey and J. C. Bayón, submitted to Inorg. Chem.

6 Paul G. Rasmussen and J. E. Anderson, Polyhedron, 2, 547 (1983).

7 W. Beck, F. Götzfried and M. Riederer, Z. anorg. allg. Chem., 423, 97 (1976).

8 P. G. Rasmussen, O. H. Bailey, J. C. Bayón and W. M. Butler, submitted to Inorg. Chem..

9 In a dimeric complex of $\mathrm{Cu}(\mathrm{I})$ we have recently studied by $\mathrm{x}$-ray diffraction the comparable angle was $81.59^{\circ}$. (Unpublished result) 